\title{
METÁSTASES EXTRACRANIANAS DE TUMORES MENINGENCEFÁLICOS
}

\author{
O. Ricciardi-CruZ * \\ Rolando A. Tenuto **
}

Caráter contraditório observado na maioria dos gliomas é a alta malignidade contraposta à pequena capacidade de produzir metástases; também causa estranheza a relativa freqüência das metástases no neuro-eixo 4 , 17 comparada com a raridade daquelas extracranianas.

Os registros de casos, particularmente os que precedem à publicação de Abbott e Love ${ }^{1}$, são, em geral pouco sistematizados, condicionando a invalidade de alguns; foram êsses autores os primeiros a procurar uma classificação que permitisse agrupar os casos de forma a assegurar validade científica. Assim, dividiram os casos registrados na literatura sôbre tumores intracranianos metastatizantes em três grupos: 1) casos provàvelmente válidos; 2) casos questionàvelmente válidos; 3) casos incertamente válidos ou inválidos, dependendo da documentação histopatológica que cada autor apresentava. Esta classificação, utilizada mais tarde por Winkelman e col..25, quando completada pelo critério mínimo de validade científica proposto por Weiss ${ }^{24}$, permite, a nosso ver, dar um valor seguro e sistematizar êsses registros. Winkelman e col. analisaram 45 casos citados na literatura dentre os quais somente $15,5 \%$ puderam ser classificados no grupo 1 de Abbott e Love. Dentro dêste mesmo conceito Weiss adotou quatro regras como critério básico de validade científica: 1) presença de tumor único no sistema nervoso central, com estrutura histológica típica de glioma; 2) história clínica que indica ser a sintomatologia inicial devida a essa neoplasia do sistema nervoso central; 3) necropsia completa e minuciosa permitindo eliminar uma localização primária extracerebral; 4) semelhança entre as estruturas histológicas do tumor primário e das metástases. Com base neste critério de Weiss, as publicações que colhemos recentemente na literatura (Paterson ${ }^{17}$, Perrin ${ }^{19}$, Dewart e col. ${ }^{5}$, Ehrenreich e Devlin ${ }^{6}$, Ley e col. ${ }^{14}$, Kruse ${ }^{13}$, Strang e col. ${ }^{20}$ ) adotam orientação mais segura, pois os autores procuram fazer a análise do valor científico de seus próprios casos; essa conduta atual não encoraja publicações semelhantes às incluídas no grupo 3 de Abbott e Love que, destituidas de documentação histopatológica ou de exame necroscópico minucioso, não podem ser creditadas.

Trabalho da Clínica Neurológica (Prof. A. Tolosa) da Fac. Med. da Univ. de São Paulo: *Neurocirurgião; ** Neurocirurgião chefe. 
A via seguida pelas células necplásicas responsáveis pelas metástases extracranianas constitui problema anátomo-fisiológico. A hipótese de serem as células veiculadas pelo liquido cefalorraqueano explica satisfatòriamente as metástases encontradas na intimidade do sistema nervoso central 4, 17, mas não pode ser lembrada para as que se localizam fora do estojo crânio-raqueano. A via linfática, em virtude da ausência de um sistema linfático encefálico, poderá explicar sòmente as metástases provenientes de neoplasias cerebrais que invadam as partes moles dos envoltórios da cabeça, atingindo o sistema Iinfático da região ${ }^{3}$. A via hematogênica, com grande freqüência responsabilizada por essas metástases, representa aparentemente um paradoxo, pois existe uma relação inversa entre a intensa vascularização cerebral e o pequeno número de metástases produzidas pelos tumores encefálicos. Entretanto, êsse paradoxo deixa de ser se considerarmos o caráter dêsses vasos; constituidos de paredes finas, as veias cerebrais em suas relações com os processos expansivos são mais propensas ao colapso que à invasão tumoral. Por outro lado, os seios da dura-máter são estruturas mais resistentes, tolerando invasões tumorais sem colapso de suas paredes; êsse caráter dos canais venosos durais permite, em alguns casos, a invasão e progressão do tumor atrivés de sua luz, atingindo estruturas extracranianas como foi ccmprovado nos relatos de Baumann 2, de James e Pagel 11 e, particularmente, no registro de Towne ${ }^{23}$, no qual o tumor, progredindo pela luz do seio sagital superior, atingiu a veia cava superior. Wolf e col. ${ }^{26}$ observaram um caso de metástases extracranianas de glioma cerebral, que teriam sido veiculados por via artificial - anastomose ventrículo-pleural - realizada em ato cirúrgico precedente.

Os tumores cerebrais que mais freqüentemente determinam metástases extracranianas, segundo as revisões de Abbott e Love 1 e de Winkelman e col. ${ }^{25}$ são os meningeomas, seguidos, em ordem de freqüência, pelos gliomas indiferenciados, tumores pituitários, tumores originários dos vasos sangüínєos e, mais raramente, pelos melanomas e corioepiteliomas. As sedes mais freqüentes dessas metástases são, em ordem decrescente: tórax (pulmão, pleura e mediastino) 1, 3, 6, 7, 8, 12, 21, 22, 24 e 25, sistema ganglionar (gânglios cervicais e do hilo pulmonar) $1,8,15,16$ e22, fígado 5,10 e $24, \operatorname{ossos}^{11} \mathrm{e}^{19}$, rins $^{2}$ e miocárdio ${ }^{9}$.

$\mathrm{Na}$ quase totalidade dos casos registrados foi feita craniotomia com extirpação do tumor cerebral primário, sendo a manipulação cirúrgica responsabilizada pela disseminação neoplásica. Entretanto, em um caso observado por Jurow ${ }^{12}$, tanto o tumor cerebral primário como a metástase constituíram achados de necropsia. A única publicação em língua portuguêsa referente ao assunto é a de Almeida Lima ${ }^{15}$ que, a nosso ver, poderia ser incluída no grupo 2 de Abbott e Love.

$\mathrm{Na}$ revisão bibliográfica que fizemos, assim como nas mais recentes referências que obtivemos da literatura, é patente a raridade dos tumores cerebrais que provocam metástases, particularmente em nosso meio, fato que justifica esta publicação. Em nosso Serviço, durante o periodo de 1945 a 1964 foram operados 912 pacientes com neoplasias intracranianas; três $(0,33 \%)$ dêstes casos apresentaram metástases extracranianas. 


\section{CASUISTICA}

CASo 1 - T.C.M., 22 anos, sexo masculino, branco, internado em 24-6-1954 (R.G. 380086). Em 1950 o paciente foi operado em outro Hospital por apresentar hipertensão intracraniana, tendo sido extirpado um tumor da região temporal esquerda; o exame histopatológico revelou tratar-se de tumor vascularizado indiferenciado. Três anos após a primeira intervenção ocorreram crises de ausências e parestesias no membro superior direito. o exame neurológico era normal, assim como o exame de fundo de ôlho. Angiografia cerebral via artéria carótida esquerda: sinais de processo expansivo na regiāo parieto-occipital. Operação: craniotomia paríeto-occipital esquerda e exerese de grande tumor encapsulado, aderente à meninge. No pós-operatório houve complicação local, traduzida por fístula com saída de líquido cefalorraqueano que permanecia na ocasião da alta do paciente. Evolução: durante os 6 meses subseqüentes à segunda intervenção cirúrgica o paciente apresentou discretas paresias no membro superior direito; a seguir surgiu supuração na incisão e osteomielite do retalho ósseo da craniotomia, o que motivou sua reinternação. Foi reoperado, tendo sido realizada a seqüestrectomia e plástica do couro cabeludo por três vêzes. No pós-operatório da terceira intervenção foram feitas aplicações de radioterapia antitumoral. Por ocasião da alta havia enfartamento ganglionar direito que regrediu após alguns dias. Um ano e 3 meses após a primeira intervenção foi notada estereoagnosia à direita, recrudescimento das sensações parestésicas, hemiparesia direita e disartria; o exame de fundo de ôlho permanecia normal; havia abaulamento da região parieto-occipital esquerda sôbre o retalho da craniotomia. O eletrencefalograma mostrou intensa desorganização da atividade elétrica cerebral na região paríeto-occipital esquerda. A angiografia cerebral via artéria carótida esquerda revelou sinais de processo expansivo na região parietal esquerda. Feita a revisão da craniotomia, foi encontrado um cisto e um nódulo mural aderente ao couro cabeludo, cuja biopsia resultou no diagnóstico histopatológico de ependimoma. O paciente teve alta dois meses após a operação, apresentando afasia motora e discreta hipoestesia no hemicorpo direito; 4 meses depois houve agravamento do quadro clínico e neurológico, sendo reinternado, vindo a falecer em 6$6-1956$.

Exame necroscópico $(41.637 / 56)$ - Pele e mucosas sem particularidades. Panículo adiposo escasso, relevos ósseos salientes. Sistema muscular e esquelético, olhos, nariz, ouvidos, bôca, ânus e genitais externos sem alteraçōes. Cabeça: couro cabeludo com cicatrizes de craniotomias na região paríeto-têmporo-occipital esquerda; extensas úlceras com aspecto grosseiramente nodular infiltrando todos os planos tegumentares. Dura-máter aderida ao plano cortical na região parieto-têmporo-occipital esquerda, substituída, no centro dessa área e ao nivel do seio sagital supeperior e foice do cérebro, por tecido branco-avermelhado de consistencia firme e com $1 \mathrm{~cm}$ de espessura. Encéfalo pesando $1.400 \mathrm{~g}$ com sulcos de compressāo ao redor das amígdalas cerebelares. Vasos sem particularidades. Soluçāo de continuidade no córtex cerebral, em correspondência com a aderência meningo-cortical. Nos cortes frontais há indícios de extirpação cirúrgica de tecido nervoso, estando o trigono colateral do ventrículo lateral esquerdo em comunicação com a superficie externa. Nas áreas occipitais há tecido neoplásico semelhante ao já descrito, porém com algumas áreas de necrose e outras de hemorragia, que infiltram, em focos, o córtex e a substância branca da face lateral do hemisfério. Dois nódulos esbranquiçados, circunscritos, situam-se profundamente, próximos ao côrno occipital do ventrículo. Ventrículos laterais dilatados e assimétricos, predominando em volume o direito. o restante dos hemisférios cerebrais, núcleos da base do telencéfalo, diencéfalo, mesencéfalo e rombencéfalo nada apresentam digno de nota. orgãos do pescoço: língua, amígdalas, faringe, laringe, esôfago e tireóide sem particularidades. Cavidade torácica: pulmões pesando $550 \mathrm{~g}$ à direita e à esquerda, de forma, volume e consistência normais. Coração e aorta sem particularidades dignas de nota. Cavidade abdominal: fígado, rins, ureteres, bexiga e genitais internos sem anormalidades. Supra-renais e hipófise normais. Sistema ganglionar: aumento de volume e da consistência dos gânglios retroauriculares, cervicais e supracla- 
viculares até $4 \mathrm{~cm}$ de diâmetro; superfície de corte de côr rósea, finamente granulosa, sem brilho, com faixas de fibrose dispostas em rêde. Exame histopatológico do tecido neoplásico da região parieto-têmporo-occipital esquerda: ependimoma com áreas de diferenciação de células da oligodendroglia (fig. 1). Exame histopatológico de um gânglio linfático: ependimoma metastático (fig. 2).

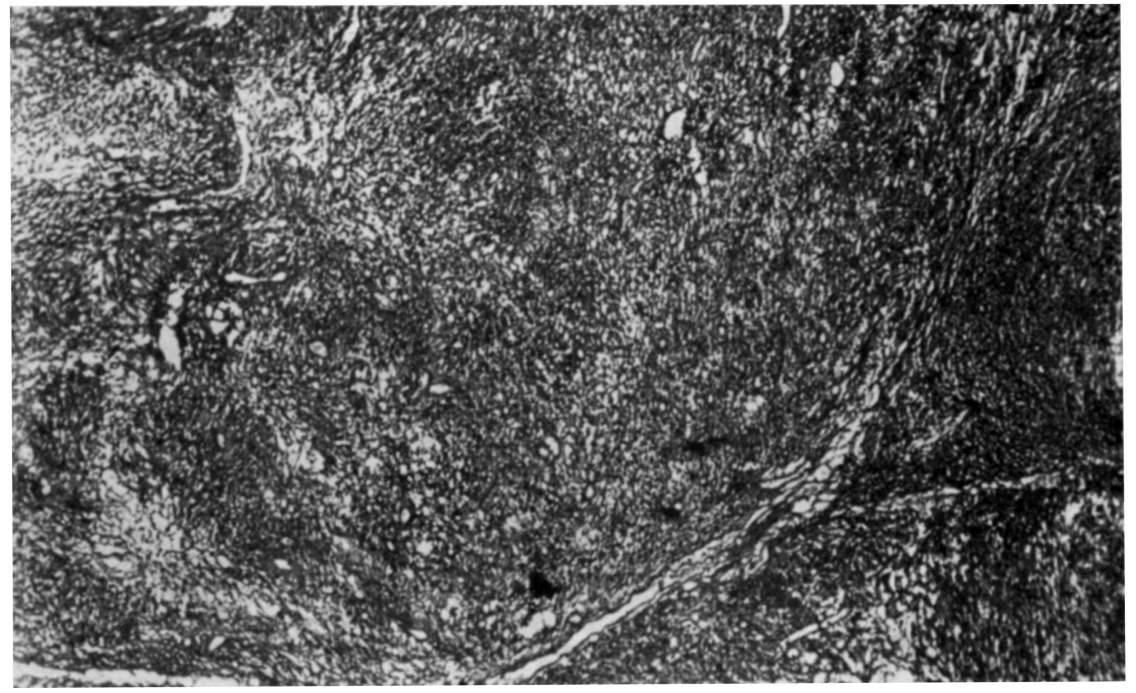

Fig. 1 - Caso 1 (T.C.M.). Corte do tumor cerebral: quadro histopatológico de ependimoma com áreas de diferenciaçōo de células da oligodendroglia $(40 \times)$.

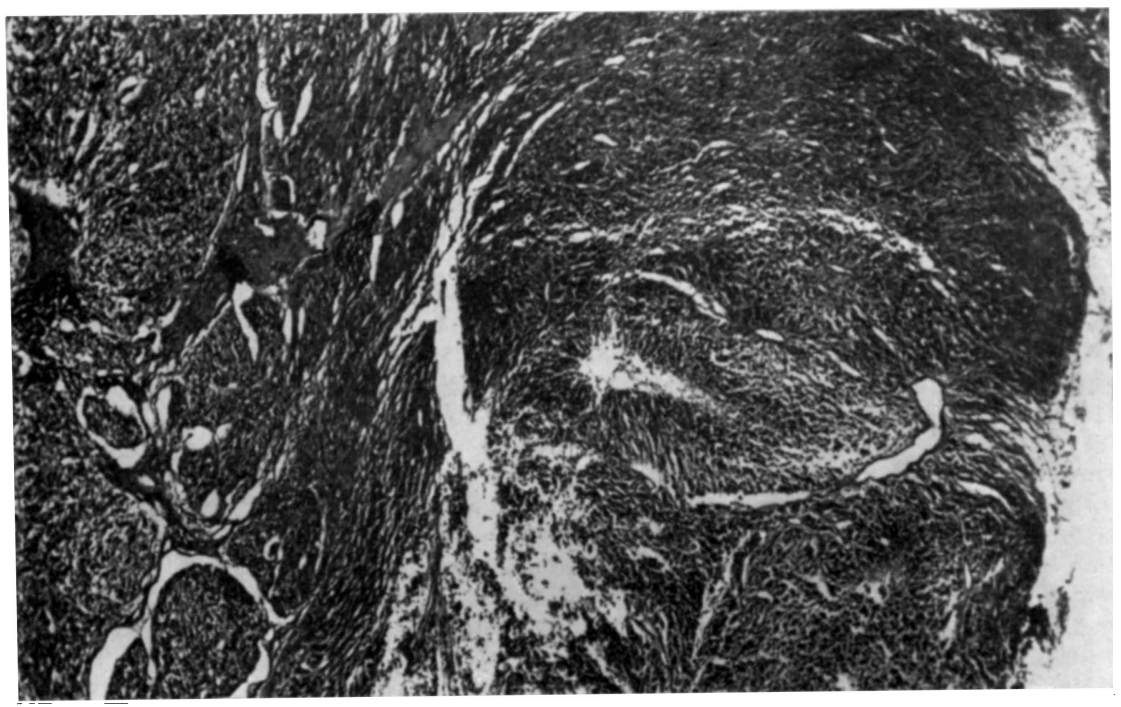

Fig. 2 - Caso 1 (T.C.M.). Ependimoma metastático em gânglio linfático. Note-se as pseudo-rosetas perivasculares em arranjo gliovascular. 
CASo 2 - M.M.A., 57 anos, sexo feminino, branca, internada em 16-10-1958 (R.G. 5171C9). Há 3 meses cefaléia intensa, difusa, com irradiação para a nuca e globo ocular direito, diminuição da acuidade visual, diplopia e vômitos; a seguir, fraqueza nos membros inferiores, principalmente à esquerda, instabilidade na marcha e quedas freqüentes. Nódulo tireoidiano duro, sem caracteres de malignidade. o exame neurológico revelava hemiparesia esquerda, estrabismo convergente e edema bilateral de papila. Angiografia cerebral via artéria carótida direita: quadro sugestivo de processo expansivo, vascularizado, na região parieto-occipital direita. Tireoidoisotopometria: área de captação baixa no lobo esquerdo da tireóide. $R a d i o-$ isotopometria craniana: área de maior captaçāo em topografia que confirma os dados sugeridos pela angiografia cerebral. Eletrencefalografia: sinais de sofrimento cerebral no hemisfério direito, predominando na região temporal. Operacão: craniotomia paríeto-occipital direita e extirpação de tumor vascularizado, enucleável, parassagital, aderido à foice do cérebro. Exame histopatológico: glioblastoma multiforme. Evolução: sem anormalidades; alta hospitalar em 16-3-1959, mantendo-se a hemiparesia esquerda. Em maio de 1959 surgiu novamente sindrome de hipertensão intracraniana, entrando a paciente em coma, pelo que foi reinternada, vindo a falecer em 11-5-1959.

Exame necroscópico (51177/59) - Pele e mucosas sem particularidades. Cabeça: no couro cabeludo incisão cirúrgica na região paríeto-occipital direita. Ossos da calota craniana sem particularidades salvo sinais de craniotomia osteoplástica. Encéfalo deformado com grande massa tumoral na região paríeto-occipital direita aderida à foice do cérebro e relacionada a uma grossa veia afluente do seio sagital superior. Exame histopatológico: glioblastoma multiforme. orgãos do pescoço e cavidade torácica sem particularidades. Cavidade abdominal: estômago, duodeno, intestinos e pâncreas sem particularidades; no figado, massa tumoral com caráter neoplásico, tendo o exame histopatológico mostrado tratar-se de metástase de glioblastoma multiforme.

Caso 3 - C.G.C., 6 anos, sexo feminino, branca, internada em 26-1-1959 (R.G. 542990). Há 3 meses e meio, cefaléia, vômitos e diminuição da acuidade visual. O exame mostrou hemiparesia esquerda e atrofia bilateral das papilas. Angiografia cerebral via artéria carótida direita: sinals de processo expansivo na região parietal direita. Operação: craniotomia fronto-parieto-temporal direita e extirpação de tumor infiltrativo invadindo a dura-máter e o osso da regiáo parietal; exerese parclal da neoplasia e das estruturas infiltratadas. Exame histopatológico: astroblastoma. Evolução: mediante telecobaltoterapia houve regressão parcial da hemiparesia. Um mês após a operaçāo, reaparecimento da hemiparesia, abaulamento do retalho do couro cabeludo e presença, à êsse nivel, de nódulos que fistulizaram demonstrando continuidade com o tumor que invadia também a regiāo correspondente à articulação têmporo-mandibular direita. A seguir a paciente entrou em coma, apresentando complicação pulmonar interpretada como broncopneumonia. obito em 5-3-1959.

Exame necroscópico $(51580 / 59)$ - Pele e mucosas sem particularidades. Cabeça: couro cabeludo com incisão cirúrgica na região fronto-têmporo-parietal direita. Ausência do retalho ósseo da craniotomia. A dura-máter e o tecido subcutâneo do couro cabeludo encontram-se invadidos por massa tumoral esbranquiçada. Encéfalo deformado, hemisfério direito destruido e, em parte, substituído por tecido neoplásico. Exame histopatológico: astroblastoma. orgãos do pescoço: massa tumoral esbranquiçada ao nivel dos gânglios cervicais. Exame histopatológico: astroblastoma. Cavidade torácica: na pleura existem vários nódulos de pequeno tamanho e côr amarelada. Exame histopatológico: astroblastoma. Cavidade abdominal: estômago, duodeno, intestino e figado sem particularidades. Ureteres, rins, supra-renais, bexiga e genitais internos sem particularidades dignas de nota. Pâncreas: duas áreas nodulares de côr branca e aspecto neoplásico. Exame histopatológico: astroblastoma. 


\section{COMENTARIOS}

O trabalho de Abbott e Love ${ }^{1}$ sôbre tumores intracranianos metastatizantes foi o primeiro a sugerir um critério de seleção de casos; a terminolcgia adotada pelos autores mostra a cautela dêsse critério e sugere um senso critico rigoroso para as futuras publicaçōes. Na revisão feita por $\mathrm{Ab}$ bott e Love ${ }^{1}$ dos 16 casos compilados na literatura, 6 foram considerados inaceitáveis, 7 casos questionáveis e 3 cientìficamente válidos. Da mesma forma, a revisão de Winkelman e col. ${ }^{25}$ considerando 45 casos, admite 14 como inaceitáveis, 23 questionáveis e 8 casos válidos. Recentemente Kruse ${ }^{13}$, atualizando a revisão de Winkelman e col. ${ }^{25}$, selecionou 20 casos provàvelmente válidos aos quais junta dois próprios. O relato mais recente é o de Strang e col. ${ }^{20}$, com ampla documentação histopatológica. Disto se conclui que existem publicações cuja documentação permite considerar alguns casos como "provàvelmente válidos".

O critério adotado para a seleção de nossos casos apoia-se nos trabalhos de Abbott e Love ${ }^{1}$ e de Weiss ${ }^{24}$. A impossibilidade circunstancial de apresentarmos documentação fotomicrográfica dos aspectos histopatológicos dos casos 2 e 3, nos obriga a classificá-los dentre os casos questionàvelmente válidos. Todavia êsses dois casos se enquadram dentro das exigências outras do critério minimo de validade científica de Weiss, motivo que nos leva a incluí-los neste trabalho, submetidos como o foram, a uma crítica prévia.

O caso 1 , a nosso ver, não tem restrição quanto a validade científica, demonstrando, a par de muitos já descritos na literatura, a possibilidade de metástases extracranianas das neoplasias intracranianas. Em todos os nossos casos houve manipulação cirúrgica. Nos casos 1 e 3 houve invasão tumoral do couro cabeludo, abrindo assim ampla via de acesso aos linfáticos dessa regiāo. No caso 2 a aderência do tumor à foice do cérebro e sua relação com uma grossa veia afluente do seio sagital superior permite supor que a via venosa tenha veiculado as metástases extracranianas; existe, neste caso, grande semelhança com aquêles descritos por Tompkins e col. ${ }^{22}$ e Towne ${ }^{23}$. Os casos 2 e 3 são de difícil avaliação científica; no entanto, o seguimento clínico-patológico demonstra que a sintomatologia foi primária no encéfalo e secundária nos órgãos afetados pelas metástases.

\section{RESUMO}

Os autores apresentam 3 casos de tumores intracranianos com metástases extracranianas; no primeiro caso o quadro clínico e a documentação histopatológica permitem sua inclusão dentre os casos provàvelmente válidos. Os outros dois casos são admitidos como questionàvelmente válidos. 


\section{SUMMARY}

Intracranial tumors with extracranial metastases.

One case of ependymoma with widespread metastases in the cervical lymph nodes and in the lungs is reported. This case is considered by the authors as a probable example of metastasizing intracranial glioma. Two other cases are presented and are considered questionable.

\section{REFERENCIAS}

1. ABBOTT, K. H. \& LOVE, J. G. - Metastasizing intracranial tumors. Ann. Surg., 118:343, 1943. 2. BAUMANN, J. - A contribution to the problem of extradural metastasis in meningeomas. Confinia Neurologica 18:394, 1958. 3. CROSS, K. R. \& COOPER, T. J. - Intracranial neoplasms with extracranial metastasis. J. Neuropath. a. Exp. Neurol., 11:200, 1952. 4. CRUZ, O. R. \& MONTENEGRO, M. R. - Meduloblastoma do cerebelo. Metástases cerebrais múltiplas após operação e radioterapia. Arq. Neuro-Psiquiat. (São Paulo) 18:46, 1960. 5. DEWART, L.; THIRY, S. \& BETZ, E. H. - Un cas de gliome cérébral avec metastases hépatiques. Ann. Anat. Path., 3:447, 1958. 6. EHRENREICH, T. \& DEVLIN, J. F. - A complex of glioblastoma and spindle-cell sarcoma with pulmonary metastasis. A.M.A. Arch. Path., 66:536, 1958. 7. GIBBS, N. M. - Meningeoma with extracranial metastasis. J. Path. Bact. (London) $76: 285,1958$. 8. GLOBUS, J. H.; LEVIN, S. \& SHEPS, J. G. - Primary sarcomatous meningeoma. J. Neuropath. a. Exper. Neurol., 3:311, 1944. 9. GROOP, A. - Uber ein metastasierendes "gliom". Zschr. Krebsforseh., 60: 590, 1955. 10. HAMBLET, J. B. - Arachnoidal fibroblastoma (meningeoma) with metastasis to the liver. Arch. Path., 37:216, 1944. 11. JAMES, T. G. I. \& PAGEL, W. - Oligodendroglioma with extracranial metastases. Brit. J. Surg., 39:56, 1951. 12. JUROW, H. N. - Psammomatosus dural endothelioma (meningeoma) with pulmonary metastasis. Arch. Path., 32:222, 1941. 13. KRUSE, F. - Meningeal tumors with extracranial metastases. Neurology 10:197, 1960. 14. LEY, A.; CAMPILLO, D. \& OLIVERAS, C. - Extracranial metastasis of glioblastoma multiforme. J. Neurosurg., 18:313, 1961. 15. LIMA, A. -- Metástase cervical de um meningeoma parassagital. Rev. Españ. Otoneuroft., 10:313, 1951. 16. MASS, L. - Occipital ependymoma with extracranial metastases. J. Neurosurg., 11:413, 1954. 17. PATERSON, E. - Distant metastases from medulloblastoma of the cerebellum. Brain 84:301, 1961. 18. PENDERGRASS, E. P. \& WILBUR, D. L. - Tumor of the brain with widespread metastasis. A report of two cases. Arch. Neurol. a. Psychiat., 19: 437, 1928. 19. PERRIN, E. V. - Extracranial metastasis from intracranial gliomata: report of two cases in children. Am. J. Clin. Path., 30:244, 1958. 20. STRANG, R. R.; TOVI, D. \& NORDESTAN, H. - Meningeoma with intracerebral, cerebellar and visceral metastasis. J. Neurosurg., 21:1098, 1964. 21. SWINGLE, A. J. - Meningeosarcoma with pulmonary metastasis. Arch. Neurol. a. Psychiat., 61:65, 1949. 22. TOMPKINS, V. N.; HAYMAKER, W. \& CAMPBELL, E. H. - Metastatic pineal tumors. A clinopathologic report of two cases. J. Neurosurg., 7:159, 1950. 23. TOWNE, E. B. - Invasion of the intracranial venous sinuses by meningeoma (dural endothelioma). Ann. Surg., 83:321, 1926. 24. WEISS, L. - A metastasizing epen- 
dymoma of the cauda equina. Cancer 8:161, 1955. 25. WINKELMAN, N. W.; CASSEL, C. \& SCHLESINGER, B. - Intracranial tumors with extracranial metastasis. J. Neuropath. a. Exper. Neurol., 11:149, 1951. 26. WOLF, A.; COWEN, D. \& STEWART, W. B. - Glioblastoma with extraneural metastasis by way of a ventriculopleural anastomosis. Tr. Am. Neurol. Ass., 79th meeting, 1954, pág. 140.

Clínica Neurológica - Faculdade de Medicina da Universidade de São Paulo - Caixa Postal 3461 - São Paulo, SP - Brasil. 